Western University

Scholarship@Western

Civil and Environmental Engineering

Civil and Environmental Engineering

Publications

Department

2020

Seismic performance of concrete core walls reinforced with shape memory alloy bars

Emad A. Abraik

Western University

Salah El-Din F. El-Fitiany

The University of Western Ontario

Maged A. Youssef

Western University, youssef@uwo.ca

Follow this and additional works at: https://ir.lib.uwo.ca/civilpub

Citation of this paper:

Abraik, Emad A.; El-Fitiany, Salah El-Din F.; and Youssef, Maged A., "Seismic performance of concrete core walls reinforced with shape memory alloy bars" (2020). Civil and Environmental Engineering Publications. 201.

https://ir.lib.uwo.ca/civilpub/201 


\title{
SEISMIC PERFORMANCE OF CONCRETE CORE WALLS REINFORCED WITH SHAPE MEMORY ALLOY BARS
}

\author{
Emad Abraik ${ }^{1}$, S. F. El-Fitiany ${ }^{1,2}$. Maged A. Youssef ${ }^{1, *}$ \\ ${ }^{1}$ Dept. of Civil and Environmental Engineering, Western University, London, Ontario, Canada \\ ${ }^{2}$ Dept. of Civil and Environmental Engineering, Alexandria University, Alexandria, Egypt
}

\begin{abstract}
Reinforced Concrete (RC) core walls are widely used to resist lateral loads because of their high flexural and torsional stiffnesses. Their seismic performance parameters, including residual displacement, floor acceleration, and residual in-plane rotation, were examined by many researchers. However, reports from previous earthquakes have highlighted the difficulties of repairs addressing their residual displacements and/or rotations. This paper addresses this problem by investigating the use of self-centering superelastic shape memory alloy (SMA) bars on the seismic performance parameters of RC core walls. A case study building is analyzed, considering both steel and SMA reinforcement, for unidirectional and bidirectional seismic excitations. Different mass eccentricities are assumed. SMA RC core walls are found to have significantly reduced floor accelerations, residual displacements, and residual in-plane rotations as compared to steel RC core walls.
\end{abstract}

KEYWORDS: Core wall; shape memory alloy; residual displacement; residual in-plane rotation; mass eccentricity

*Corresponding Author, email: youssef@uwo.ca, Phone: 1-519-661-2111 Ext. 88661 


\section{Introduction}

Reinforced concrete (RC) structural walls are widely used to resist lateral loads. They are expected to experience significant damage following exposure to strong seismic events $[1,2,3,4]$. This fact has led to numerous experimental and analytical studies to enhance their seismic performance $[5,6,7]$.

$\mathrm{RC}$ core walls represent a common and cost-effective solution for the lateral load system of buildings. Their shape varies from a simpler U-shape to more complex shapes. They have the advantage of resisting lateral loads in two directions as well as mitigating the out-of-plane instability experienced by RC walls [8,9].

$\mathrm{P}^{\prime}$ egon et al. [10] tested U-shaped RC walls under different load patterns and observed that their failure was initiated by fracture of the longitudinal bars followed by crushing of the compression flange. Beyer [11] tested two half-scale U-shaped RC walls under bi-directional cyclic loading. The first wall failed due to bar fracture, whereas the second wall failed due to web failure and diagonal shear cracks. Lowes et al. [12] tested three identical U-walls under quasi-static cyclic loading. Different types of failure modes, including sliding at the wall base, bar fracture, and concrete crushing, were observed.

The recent efforts to achieve resilient structures covered improving the post-earthquake functionality of buildings by using various types of dampers and novel materials, including superelastic shape memory alloys (SMA) $[13,14]$. The use of SMA bars in RC elements have been found to adequately dissipate the seismic energy, while significantly reducing seismic residual deformations [15]. SMA has two fundamental properties: the shape memory effect (SME) and superelasticity (SE). SME is the ability of atoms to reassemble, causing the material to regain its original shape when heated [16]. SE is a stress-induced transformation between the austenite and 
martensite phases which causes the material to recover its shape, even after undergoing large inelastic deformations, which is shown in Figure 1. $\mathrm{f}_{\mathrm{y}-\mathrm{SMA}}$ defines the SMA critical stress, which represents the start of the martensite stress-induced transformation, and ESMA is the elastic modulus of SMA.

Several studies have addressed the use of SMA material in seismic applications, including SMA braces [17,18], beam-column joints [19], RC beams [20,21], steel connections [22,23], and bridge structures [24]. The seismic performance of SMA RC frames experiencing different levels of seismic excitations was also examined [25]. Results showed that the use of SMA bars had led to significant reductions in the seismic residual deformations for the RC elements as well as RC frames. These research efforts have led to utilizing SMA in the piers of a bridge, which was part of the State Route 99 Alaskan Way Viaduct project in the Sodo district of Seattle, WA, USA [26]. Utilizing the SMA as reinforcement for RC walls was examined in several studies. Abdulridha [27] tested a slender wall reinforced with SMA bars in the wall boundaries. The test results showed the capability of SMA to reduce the residual displacements and the associated repair costs. Abraik and Youssef [15] investigated the seismic performance and vulnerability of SMA RC walls and confirmed the superior seismic performance of SMA RC walls as compared to steel RC walls. Abraik and Youssef $[28,29]$ concluded that the location of SMA bars has a significant influence on the seismic performance of a three-story SMA RC wall. The use of SMA material was extended to retrofitting of RC walls by Effendy et al. [30]. Results showed that the retrofitted RC walls tolerated higher seismic loads and provided higher displacement capacities as compared to RC walls reinforced with steel bars (steel RC walls).

The nonlinear three-dimensional seismic behaviour of SMA RC core walls was not examined in the literature. This paper addresses this shortcoming by extending the previous research efforts, 
which focused on SMA RC walls to RC core walls. The extension requires accounting for the three-dimensional behaviour, while modeling the core walls. The following sections provide details of the assumptions and validation of the utilized modeling technique and a numerical study to examine the benefits of utilizing SMA bars in RC core walls.

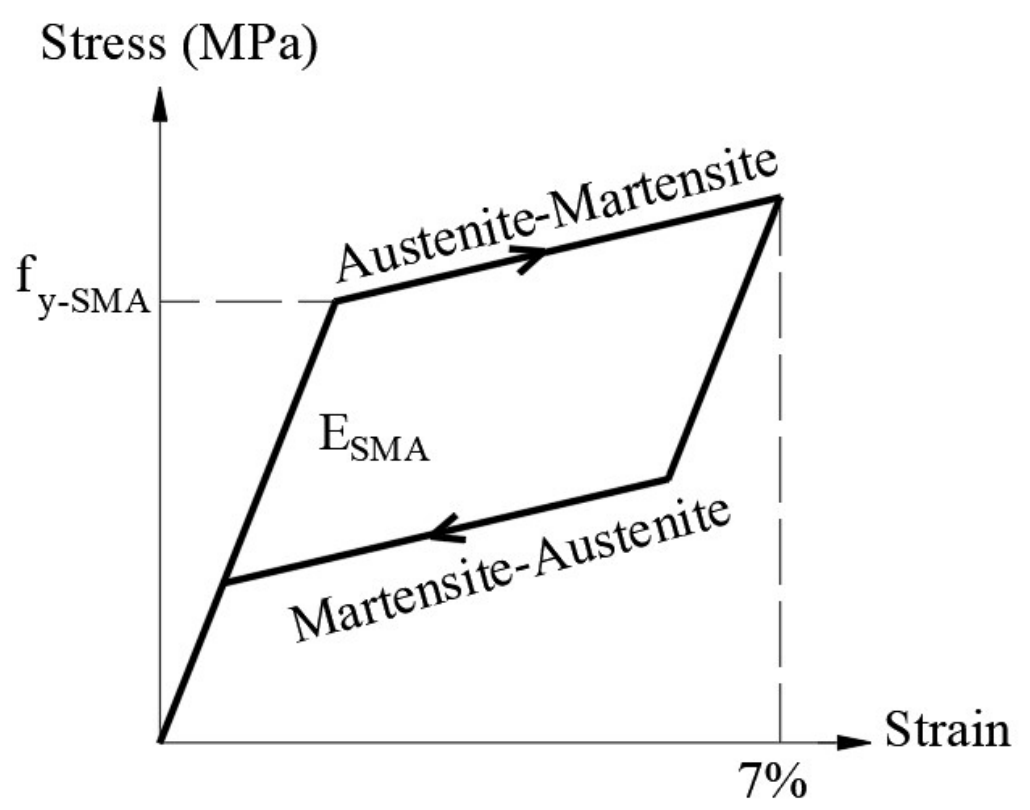

Figure 1. Loading and unloading of SMA bar

\section{Numerical Model}

The wide column model (WCM), developed by Clough et al. [31] for plane RC walls, was later extended by MacLeod and Hosny [32] to be used for non-planar walls. The model consists of vertical frame elements located at the center of the webs and flanges. The vertical elements are connected with horizontal rigid links, as shown in Figure 2. To account for the shear flexibility of the RC core wall, each vertical frame element is divided into two elements that are connected using zero-length in-plane and out-of-plane shear springs [33].

The finite element software Open System for Earthquake Engineering Simulation (OpenSees) [34] is used in the analysis. Nonlinear displacement beam elements are used to model the vertical frame 
elements. The vertical spacing between the horizontal rigid links $\left(\mathrm{h}_{\mathrm{sp}}\right)$ is taken equal to one-fifth of the shear span of the core wall (wall height), as recommended by Stafford-Smith and Girgis [35]. The in-plane stiffness $\left(\mathrm{K}_{\mathrm{s}}\right)$ of the shear springs is calculated using Eq 1, and the out-of-plane stiffness is taken as $25 \%$ of $\mathrm{K}_{\mathrm{s}}$, as recommended by Beyer [11]. 2.5\% Rayleigh damping is assumed.

$$
\mathrm{K}_{\mathrm{s}}=\frac{\mathrm{G}_{\mathrm{c}} \mathrm{A}_{\mathrm{sh}}}{\mathrm{h}_{\mathrm{sp}}}
$$

where $G_{c}$ is the concrete shear modulus and $A_{\text {sh }}$ is the shear area taken as $80 \%$ of the gross area.

Figures 3(a) and 3(b) show the constitutive stress-strain relationships developed by Mander and Priestley [36] and Menegotto and Pinto [37], which are used to model concrete and steel reinforcement, respectively. Where $f_{c}$ ' is the concrete compressive strength, $\mathrm{k}$ is the confinement factor, $E_{s}$ is the elastic modulus of steel bars, $f_{y}$ is the yield stress of the steel bars, and $f_{u}$ is the ultimate strength of the steel bars. The SMA reinforcement is represented using the self-centering uniaxial material proposed by Christopoulos et al. [38] and shown in Figure 3(c). The SMA is assumed to have an asymmetric bilinear stress-strain relationship with $\mathrm{E}_{\mathrm{SMA}}$ of $38,000 \mathrm{MPa}$ and $\mathrm{f}_{\mathrm{y} \text {-SMA }}$ of $380 \mathrm{MPa}$.

The global failure criteria proposed by TBI [39] are adopted in this analysis, i.e., global failure is assumed to correspond to a mean inter-story drift of 3\%, a maximum inter-story drift of $4.5 \%$, a mean residual drift of $1 \%$, or a maximum residual drift of $1.5 \%$. Criteria defining local failure are taken as follows: a strain of 5\% for the steel bars [40], a strain of $7 \%$ for the SMA bars, and a concrete compression strain of $2 \%[40]$. 


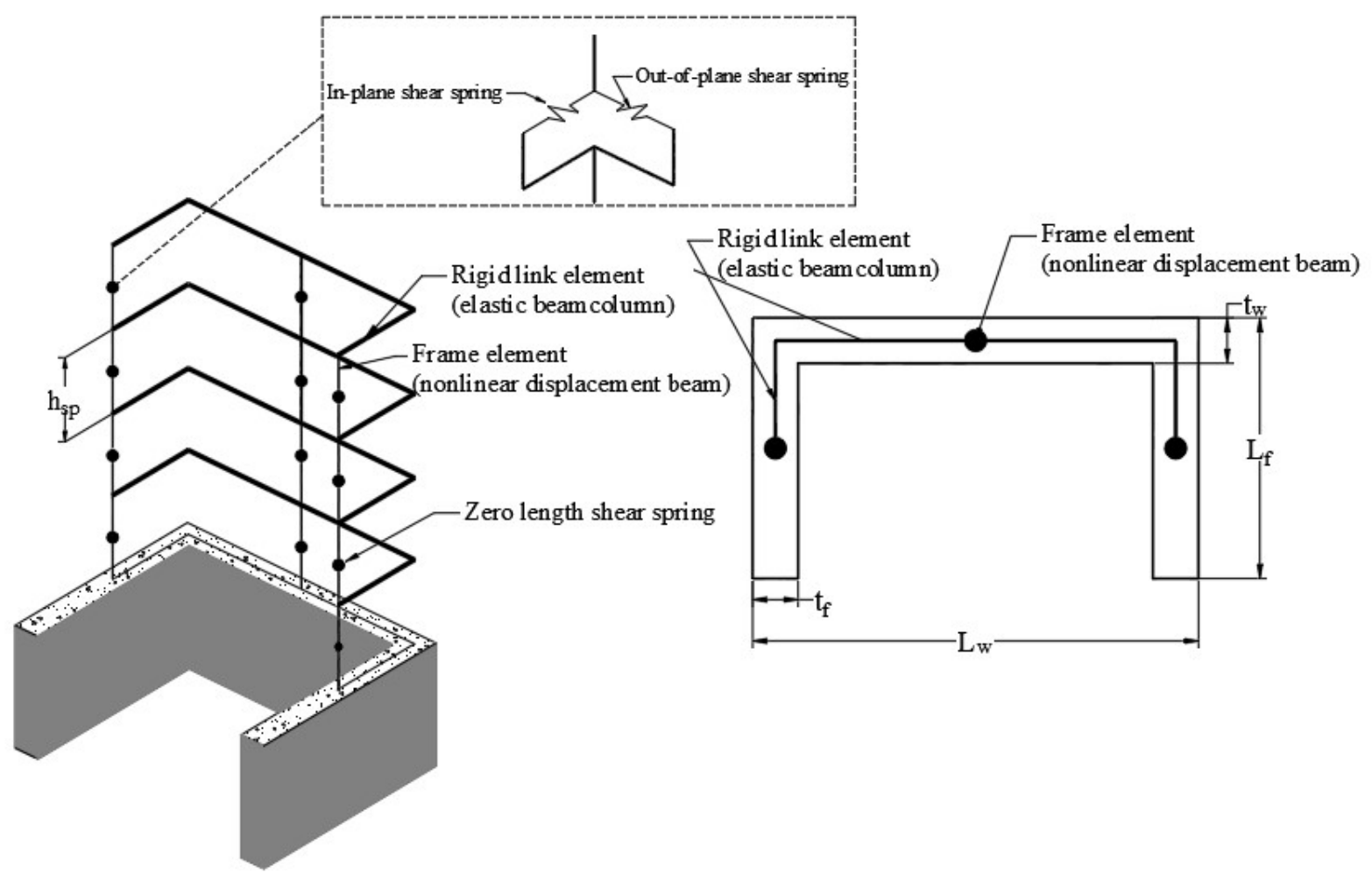

Figure 2. Wide column analytical model
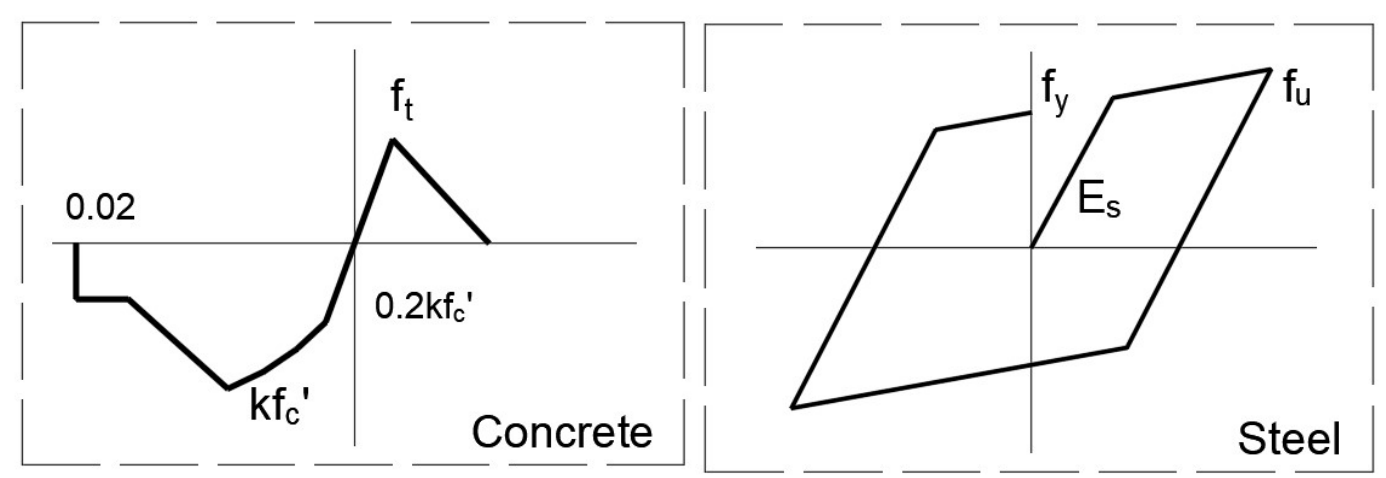

(a)

(b)

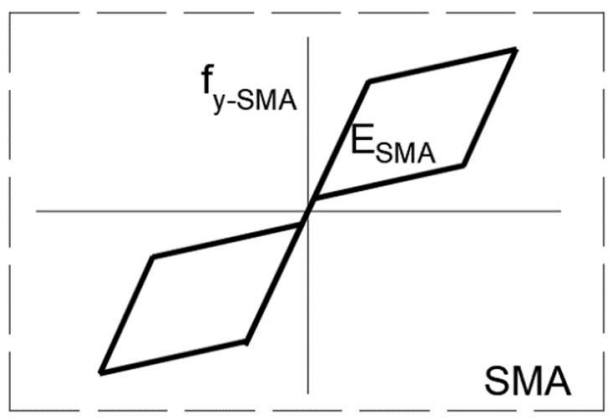

(c)

Figure 3. Stress-strain relationship of (a) concrete; (b) steel bars; (c) SMA bars 


\subsection{Model Validation}

The numerical model is validated by comparing its results with the experimental data by Beyer [11]. The U-shape RC core wall, shown in Figure 4(a), is selected as a validation case. The tested wall has a shear span ratio, i.e., moment/shear $(\mathrm{M} / \mathrm{V})$ of 2.95 and a wall thickness of $150 \mathrm{~mm}$. The ratios of the web thickness $\left(t_{W}\right)$ to the web length $\left(l_{W}\right)$ and the flange thickness $\left(t_{f}\right)$ to the flange length $\left(\mathrm{L}_{\mathrm{f}}\right)$ are 0.12 and 0.14 , respectively. Meanwhile, the uniformly distributed vertical and horizontal reinforcement ratios are $0.71 \%$ and $0.30 \%$, respectively. The wall was tested under a constant axial load of $780 \mathrm{kN}$. The four considered pushover lateral load directions; parallel to the web (Load 1), parallel to flanges \& web in tension ( Load 2), parallel to flange \& web in compression (Load 3), and diagonal (Load 4) are shown in Figure 4(b). Figure 5 shows a comparison between the experimental and numerical results. The model accurately captures the displacement at failure and load capacity with a maximum displacement error of $7.8 \%$ for load 2 and $7.2 \%$ for load 3 .

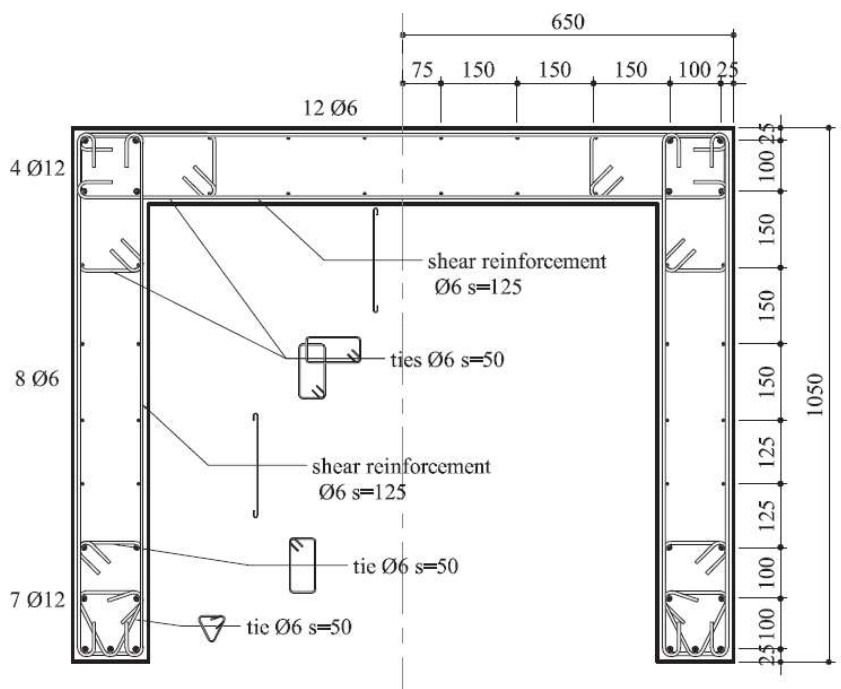

(a)

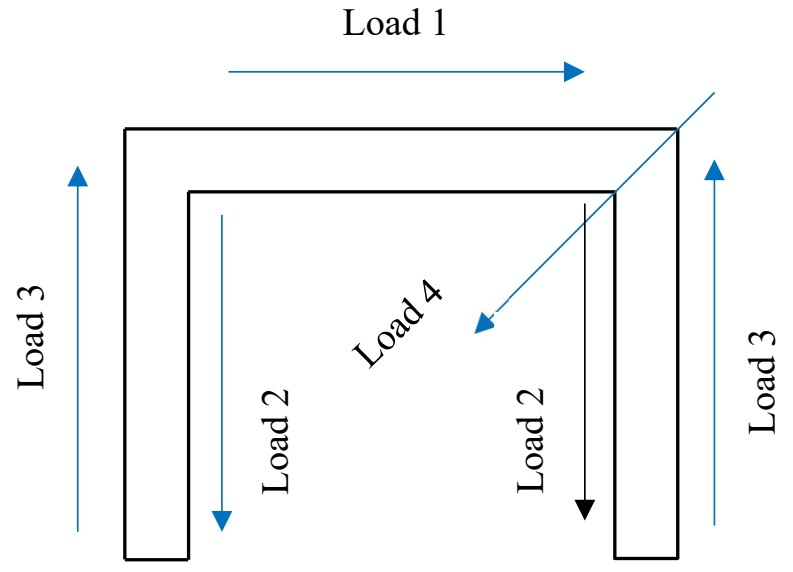

(b)

Figure 4. Core Wall tested by Beyer [11] (a) core wall details; (b) load directions 


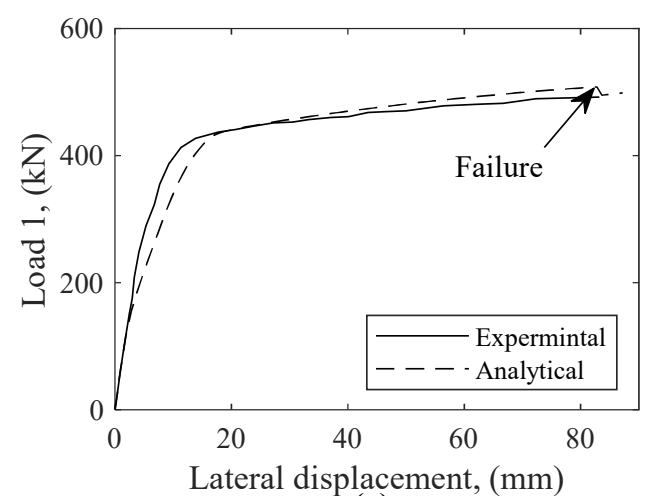

(a)

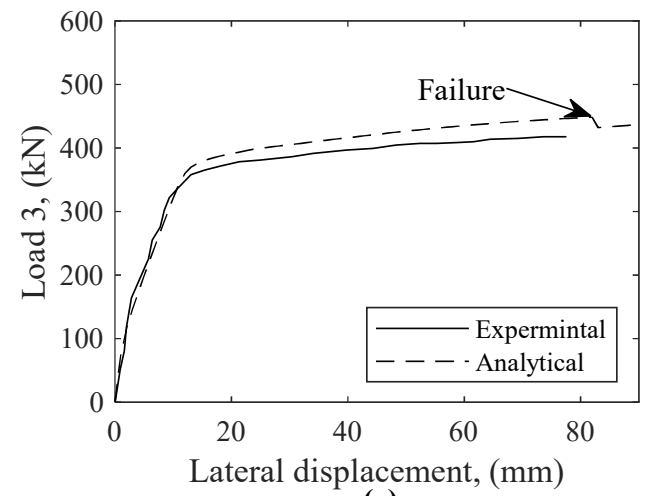

(c)

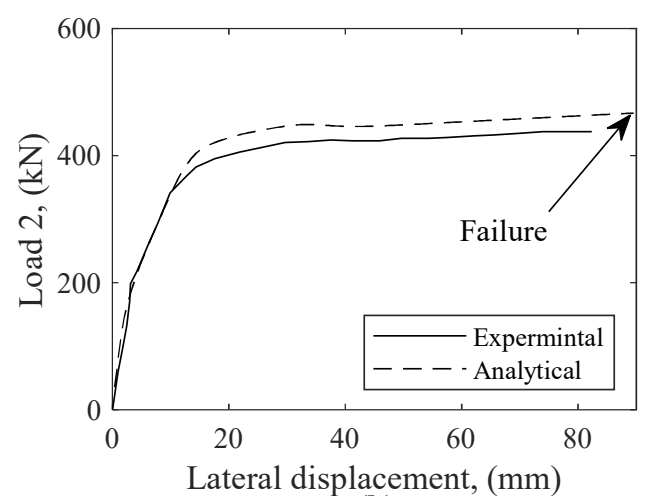

(b)

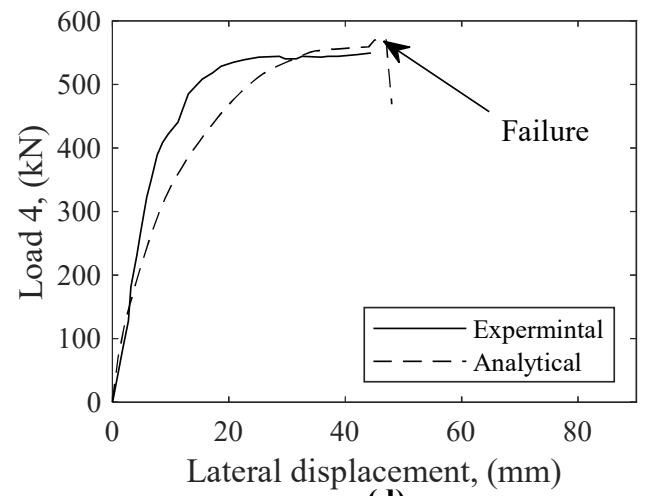

(d)

Figure 5. Numerical model versus experimental data: (a) load 1; (b) load 2; (c) load 3; (d) load 4

\section{Case Study Building:}

A nine-story RC commercial building, shown in Figure 6(a), is assumed to be located in Vancouver, BC. The selected building is $28 \mathrm{~m}$ by $28 \mathrm{~m}$ with a typical story height of $3.40 \mathrm{~m}$. The concrete core wall is designed as a ductile $\mathrm{RC}$ wall per CSA A23.3 [41]. The force modification factor $\left(\mathrm{R}_{\mathrm{d}}\right)$ and overstrength factor $\left(\mathrm{R}_{0}\right)$ are taken equal to 3.5 and 1.6, respectively, as per NBCC [42]. The concrete compressive strength and the steel yield strength are assumed to be $30 \mathrm{MPa}$ and $400 \mathrm{MPa}$, respectively. The soil profile is class $\mathrm{D}$. The total dead weights of a typical story, and the roof (including 25\% snow load) is 5,884 $\mathrm{kN}$ and 7,140 kN, respectively. Assuming that the total lateral load is resisted by the core wall, Figure 6(a) shows the locations of the center of mass (CM) and the center of rigidity (CR). The axial gravity load supported by the core wall is assumed to be $6.6 \%$ of its 
axial capacity. The influence of accidental torsion is accounted for by assuming a torsional eccentricity of $10 \%$ in both directions [41]. The dimensions and reinforcement details of the steel RC core wall are shown in Figure 6(b).

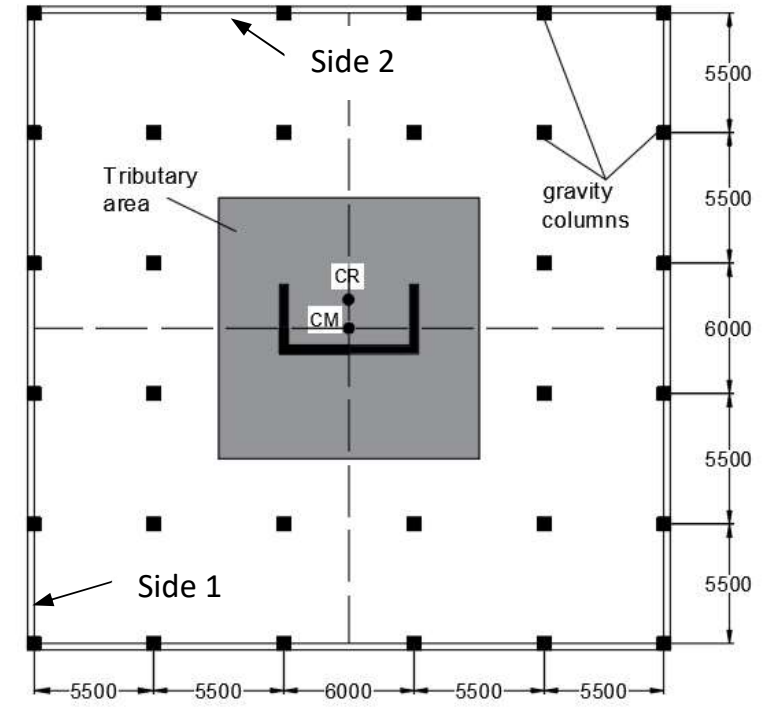

(a) Building layout

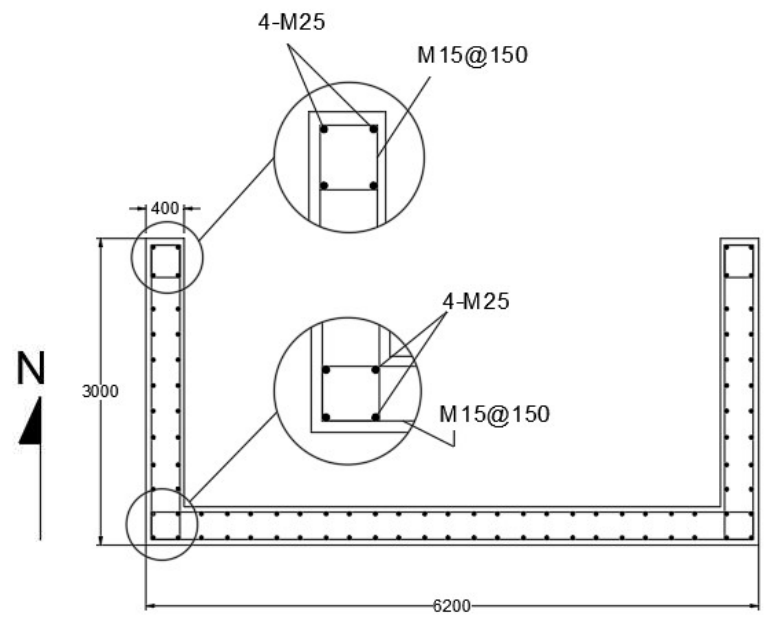

(b) core wall reinforcement

Figure 6. Selected building: (a) building plan view; (b) core wall details

For the SMA RC core wall, SMA bars are assumed to replace the steel bars in the plastic hinge zone. Plastic hinge length can be calculated using the minimum length given by Eq 2(a) or 2(b) [43] or using Eq 3 [41].

$\mathrm{L}_{\mathrm{p}}=0.08 \mathrm{H}+0.022 \mathrm{~d}_{\mathrm{b}} \mathrm{f}_{\mathrm{y}}, \mathrm{MPa}$

$\mathrm{L}_{\mathrm{p}}=0.2 \mathrm{~L}_{\mathrm{w}}+0.044 \mathrm{H}, \mathrm{MPa}$

$\mathrm{L}_{\mathrm{p}}=0.5 \mathrm{~L}_{\mathrm{w}}+0.1 \mathrm{H}, \mathrm{MPa}$

where $H$ is the effective wall height, $d_{b}$ is the diameter of the longitudinal bars, $f_{y}$ is the yield strength in $(\mathrm{MPa})$, and $\mathrm{L}_{\mathrm{w}}$ is the wall-length parallel to the loading direction. 
To decide on the equation to use to estimate the length of the SMA bars, the U-shaped RC core wall (shown in Figure 4) was subjected to cyclic loading after replacing the steel bars in the plastic hinge zone with SMA bars. Two lengths for the SMA bars were examined, which are based on the plastic hinge length given by Beyer et al. [43] and CSA A23.3 [41]. Figure 7 shows the cyclic response of the SMA RC core walls for three loading directions. The residual displacement was not affected by the length of the SMA bars. However, the plastic hinge length, recommended by Beyer et al. [43], resulted in a lower lateral drift in the diagonal direction, which is a design advantage. Therefore, Eqs 2(a) and 2(b) are utilized to determine the SMA length for the casestudy core wall. The diameter of the SMA bars was taken equal to the diameter of the steel bars.

The designed core walls are first analyzed to evaluate the structural periods (T). The full later load is assumed to be resisted by the core wall. The structural period for the east-west direction $\left(\mathrm{T}_{\mathrm{E}-\mathrm{W}}\right)$, north-south direction $\left(\mathrm{T}_{\mathrm{N}-\mathrm{S}}\right)$, and torsion $\left(\mathrm{T}_{\mathrm{t}}\right)$ of the steel RC core wall are found to be 3.27, 1.38, and 0.55 seconds, respectively. Thus, the building is not considered a tall structure as $\mathrm{T}<3.5 \mathrm{~s}$. For the SMA RC core wall, the structural periods were slightly different and are shown in Table 1.

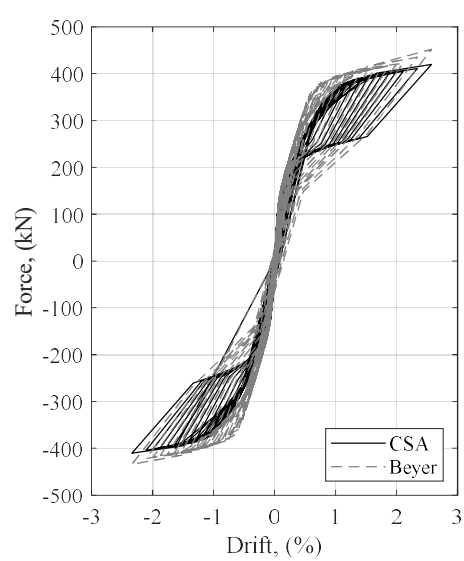

(a)

(a)

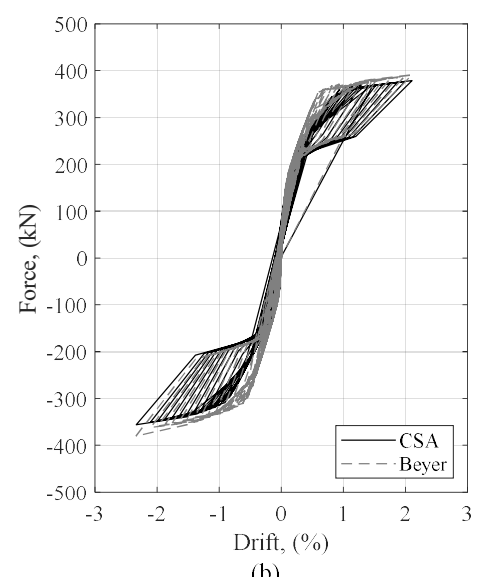

(b)

(b)

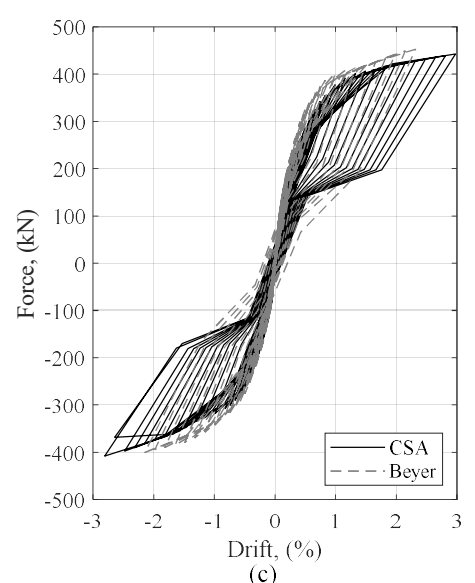

(c)

Figure 7. Cyclic response of SMA core wall with different length for the SMA bars: (a) load parallel to web; (b) load parallel to flange; (c) load in the diagonal direction 
Table 1. Structural periods (seconds)

\begin{tabular}{|c|c|c|c|c|c|c|}
\hline \multirow{2}{*}{ Period } & \multicolumn{6}{|c|}{ Torsional Eccentricity } \\
\cline { 2 - 7 } & \multicolumn{2}{|c|}{$5 \%$} & \multicolumn{2}{c|}{$10 \%$ (Design) } & \multicolumn{2}{c|}{$20 \%$} \\
\cline { 2 - 7 } & Steel & SMA & Steel & SMA & Steel & SMA \\
\hline $\mathrm{T}_{\mathrm{E}-\mathrm{W}}$ & 2.66 & 2.79 & 3.27 & 3.40 & 4.07 & 4.11 \\
$\mathrm{~T}_{\mathrm{N}-\mathrm{S}}$ & 1.39 & 1.45 & 1.38 & 1.42 & 1.34 & 1.35 \\
$\mathrm{~T}_{\mathrm{t}}$ & 0.47 & 0.49 & 0.55 & 0.56 & 0.73 & 0.73 \\
\hline
\end{tabular}

\section{Nonlinear Seismic Analysis}

To evaluate the effect of torsional eccentricity on the seismic performance of core walls, the building is analyzed at $5 \%, 10 \%$, and $20 \%$ torsional eccentricities. Table 1 summarizes the structural periods considering different torsional eccentricities. The first period was found to increase with increasing the mass eccentricity due to the coupling between torsional mode and the first mode. Dynamic analysis is then conducted for the steel and SMA RC cores, considering the three mentioned torsional eccentricities.

Six ground motions, given in Table 2, were selected from the PEER ground motion database [44]. They were scaled to match the design spectra using the Mean Square Error (MSE). The scaled ground motions cover periods from $0.2 \mathrm{~T}_{2}$ to $1.5 \mathrm{~T}_{1}$ for both the steel and SMA RC core walls, where $\mathrm{T}_{1}$ and $\mathrm{T}_{2}$ are the first and second structural periods at the $10 \%$ design mass eccentricity. Figure 8 shows the spectral acceleration for the selected ground motions as well as the maximum considered earthquake (MCE) for Vancouver, BC. 


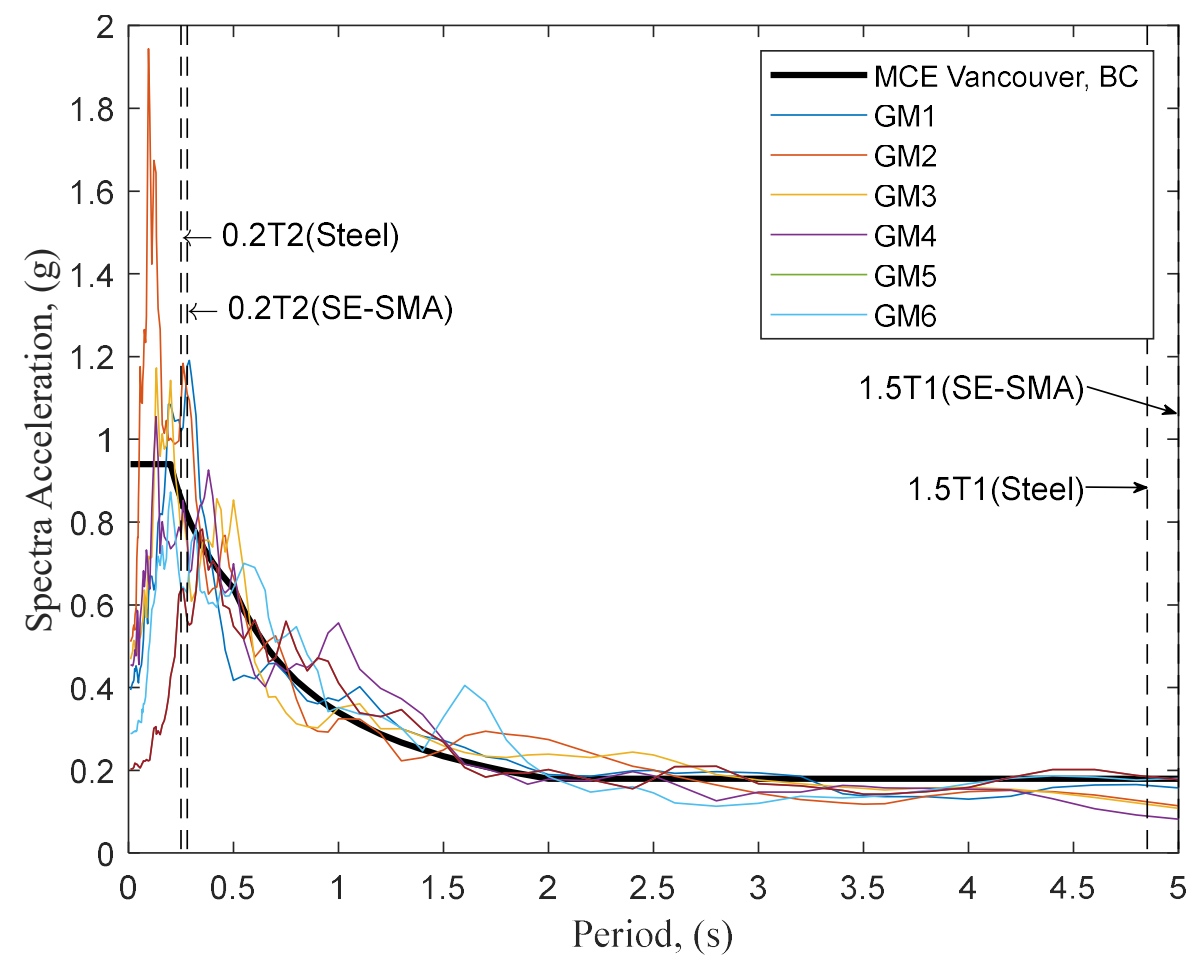

Figure 8. Design spectra and ground motions

Table 2. Properties of chosen ground motions

\begin{tabular}{|c|l|l|c|c|}
\hline $\begin{array}{l}\text { Ground } \\
\text { Motion }\end{array}$ & \multicolumn{1}{|c|}{ Earthquake } & \multicolumn{1}{|c|}{ Station } & Magnitude & Scale Factor \\
\hline GM1 & Imperial Valley-06 & Calipatria Fire & 6.53 & 2.60 \\
GM2 & Imperial Valley-06 & El Centro Array \#1 & 6.53 & 2.00 \\
GM3 & Lander & Mission Creek & 7.28 & 2.29 \\
GM4 & Kobe & Abeno & 6.90 & 1.40 \\
GM5 & Chi-Chi & TCU038 & 7.62 & 1.00 \\
GM6 & Darfield & Hulverstone Drive Pumping & 7.00 & 1.21 \\
\hline
\end{tabular}

The analysis was first conducted by considering each of the seismic excitations to be acting on the core wall either in the E-W direction or the N-S direction. This was followed by bidirectional analysis, where the seismic excitations were assumed to be applied in both directions simultaneously. Floor accelerations, lateral displacements, inter-story drift ratios, and residual displacements were determined at the building center of rigidity. The diaphragm rotation was determined with reference to the building corners. 


\subsection{Unidirectional Seismic Excitations}

Each ground motion is applied independently in each direction ( 72 cases in total). Figure 9 shows the mean floor acceleration along the building height relative to the peak ground acceleration (PGA) considering different torsional eccentricities. The difference in the floor accelerations between the steel and the SMA RC core walls is negligible, considering $5 \%$ and $10 \%$ eccentricities. For $20 \%$ torsional eccentricity, using SMA bars decreases the floor accelerations by an average value of $8 \%$. This reduction might be due to the lower SMA stiffness as compared to the conventional steel stiffness. The reduced floor accelerations reflect a reduction in the damage to non-structural components.

Figures 10 and 11 show the mean maximum lateral displacements and inter-story drift ratios considering different torsional eccentricities. A negligible difference exists in the E-W direction between the steel and the SMA core walls. The calculated lateral displacements in the E-W direction decrease with the increase in torsional eccentricity. The decline in lateral displacements at high torsional eccentricity may be due to the associated increase in the structural period, Table 1. In the N-S direction, the lateral displacement of the SMA RC core wall is lower than the steel RC core wall by about $7 \%$ at $5 \%$ torsional eccentricity. The results of the mean inter-story drifts (MID) in both directions have the same trend as obtained from lateral displacements. The SMA bars decrease the mean inter-story drifts in the N-S direction by about $20 \%$ on average for $5 \%$ and $10 \%$ torsional eccentricity. This is because the steel yielding strain is much lower than the SMA strain limit. 

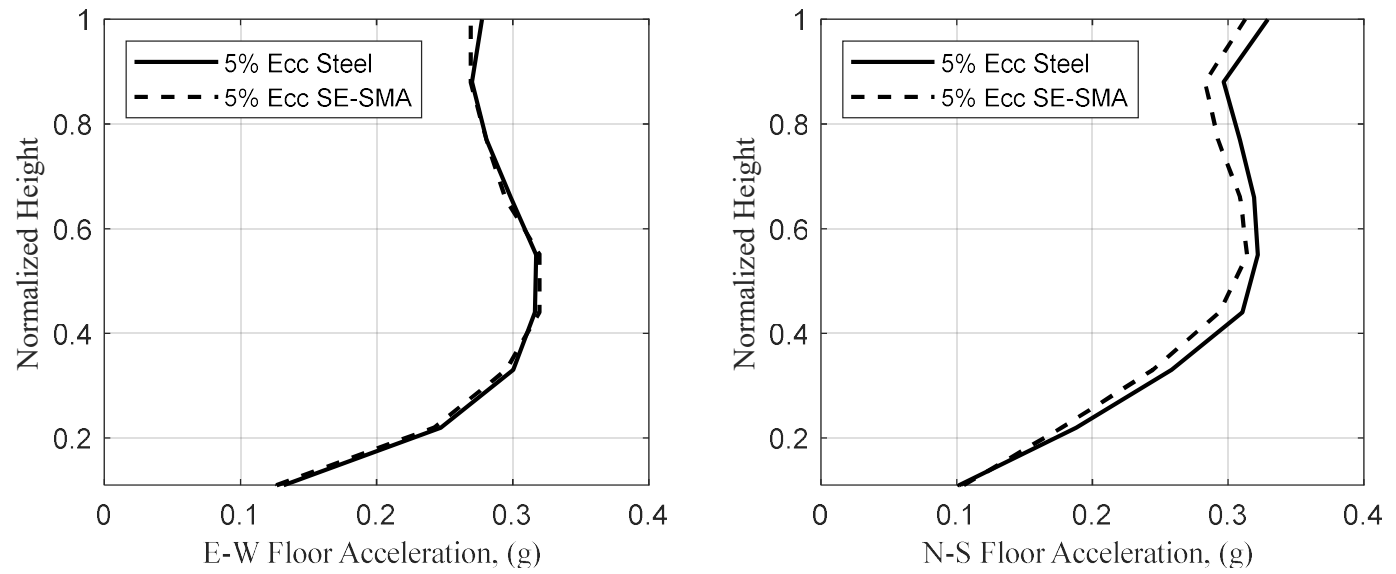

(a)
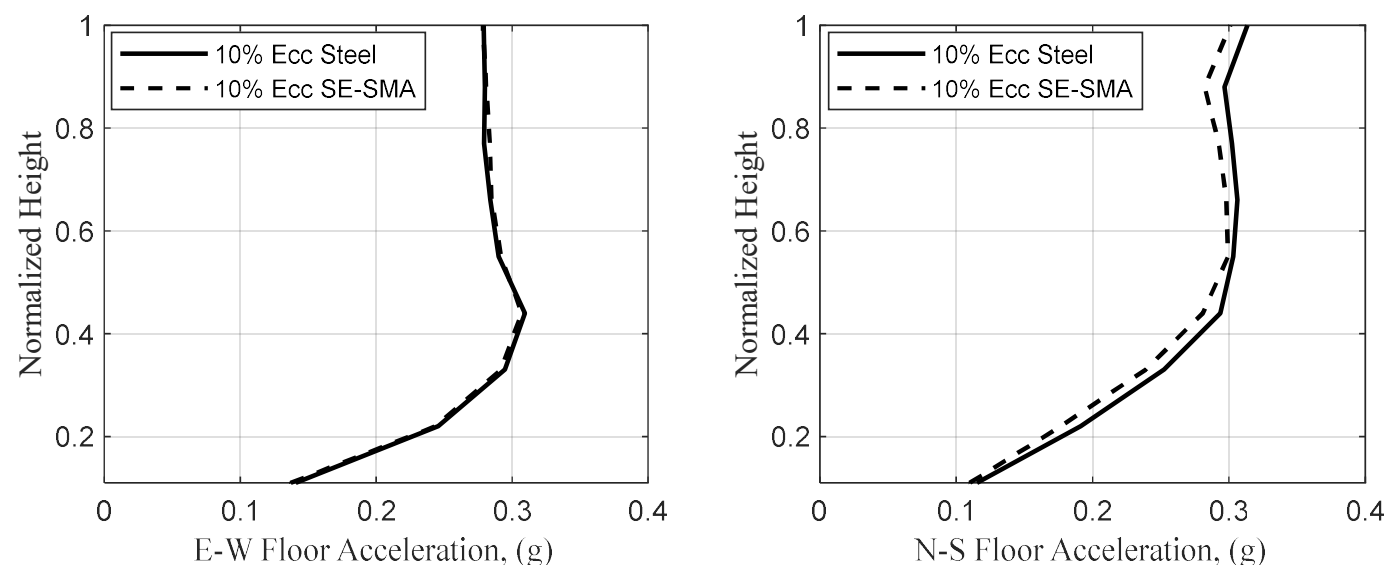

(b)
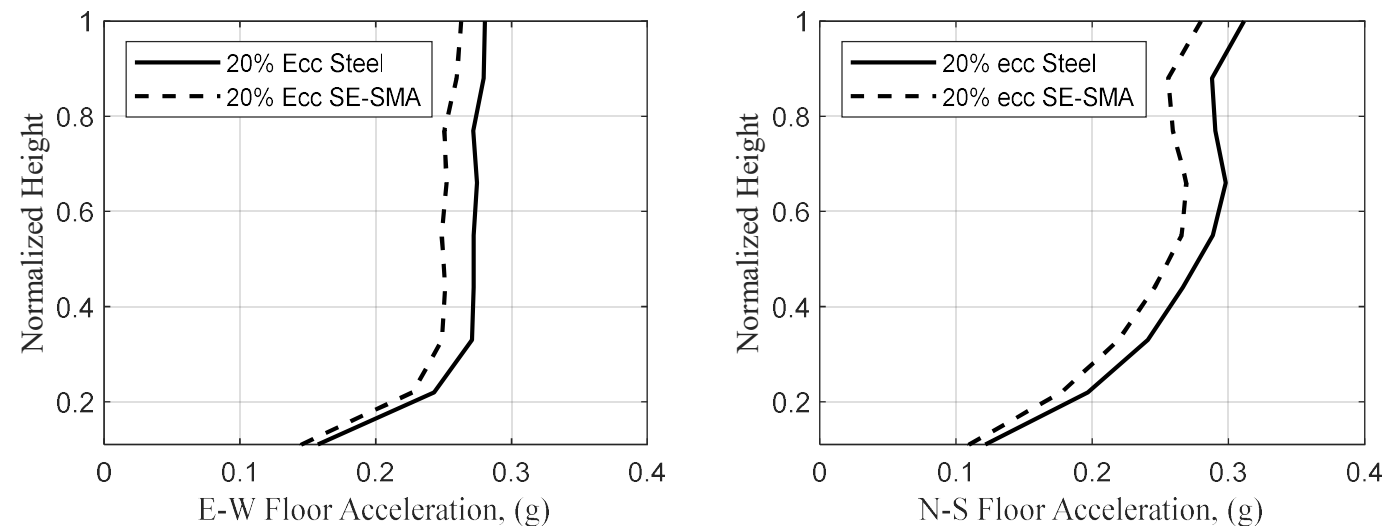

(c)

Figure 9. Mean floor accelerations: (a) 5\% Eccentricity; (b) 10\% Eccentricity; (c) 20\% Eccentricity 

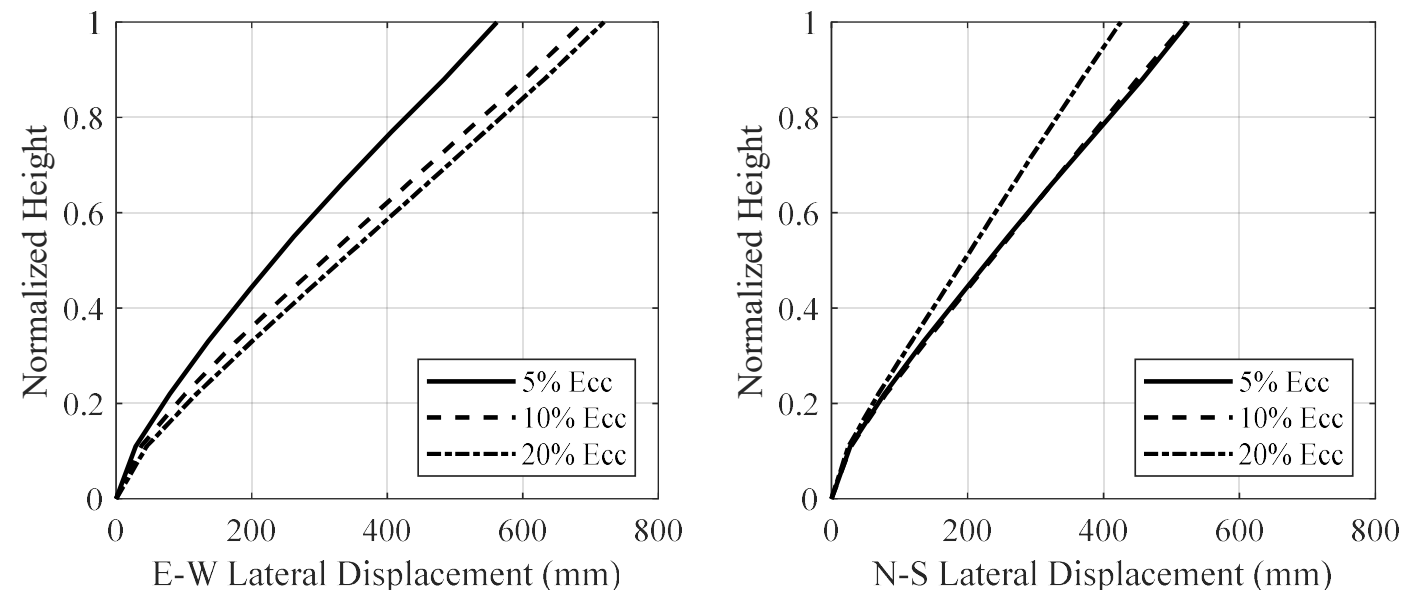

(a)
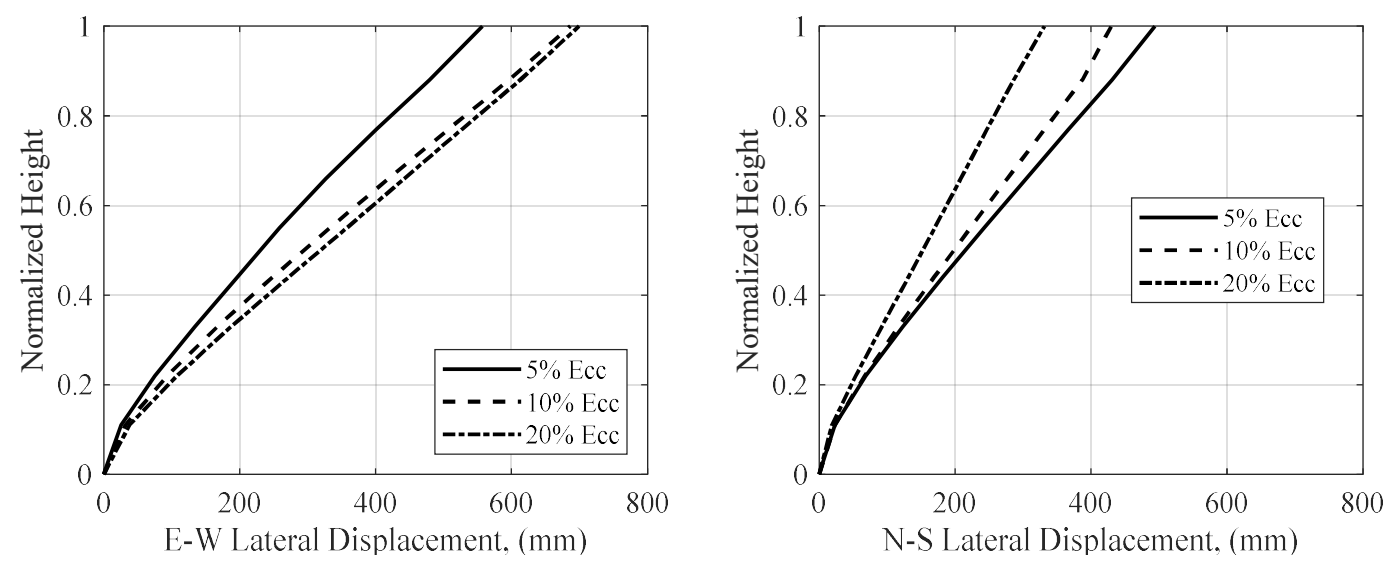

(b)

Figure 10. Mean maximum lateral displacements: (a) steel RC core wall; (b) SMA RC core wall 

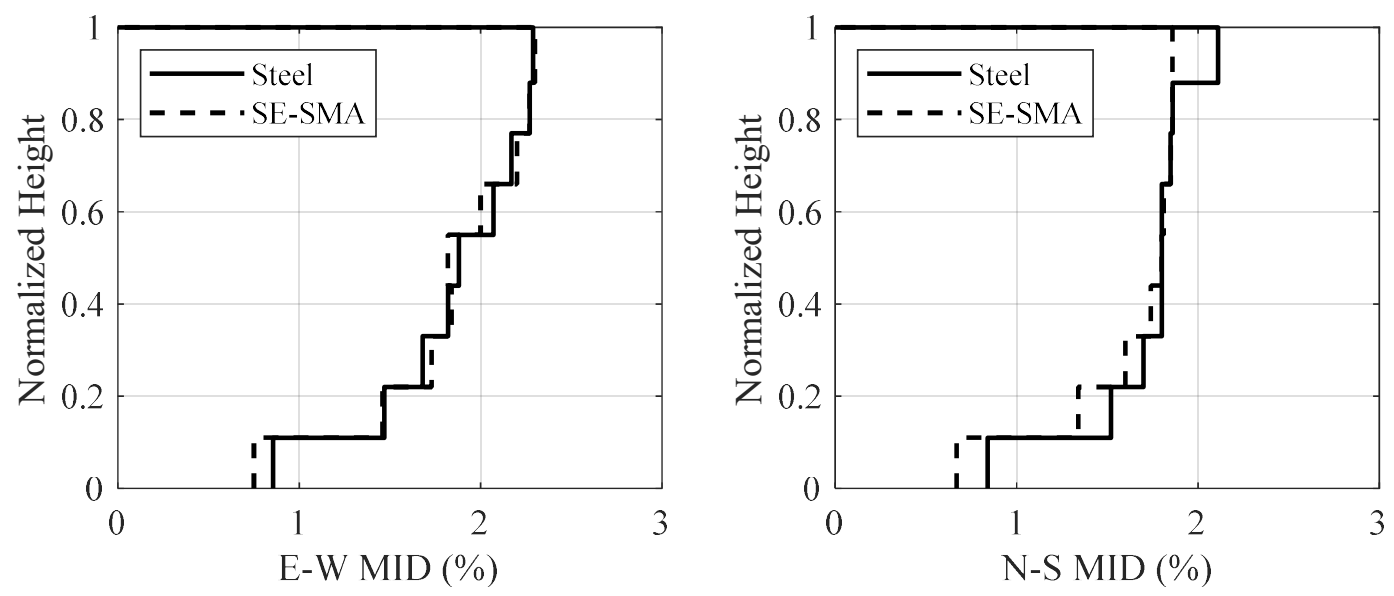

(a)
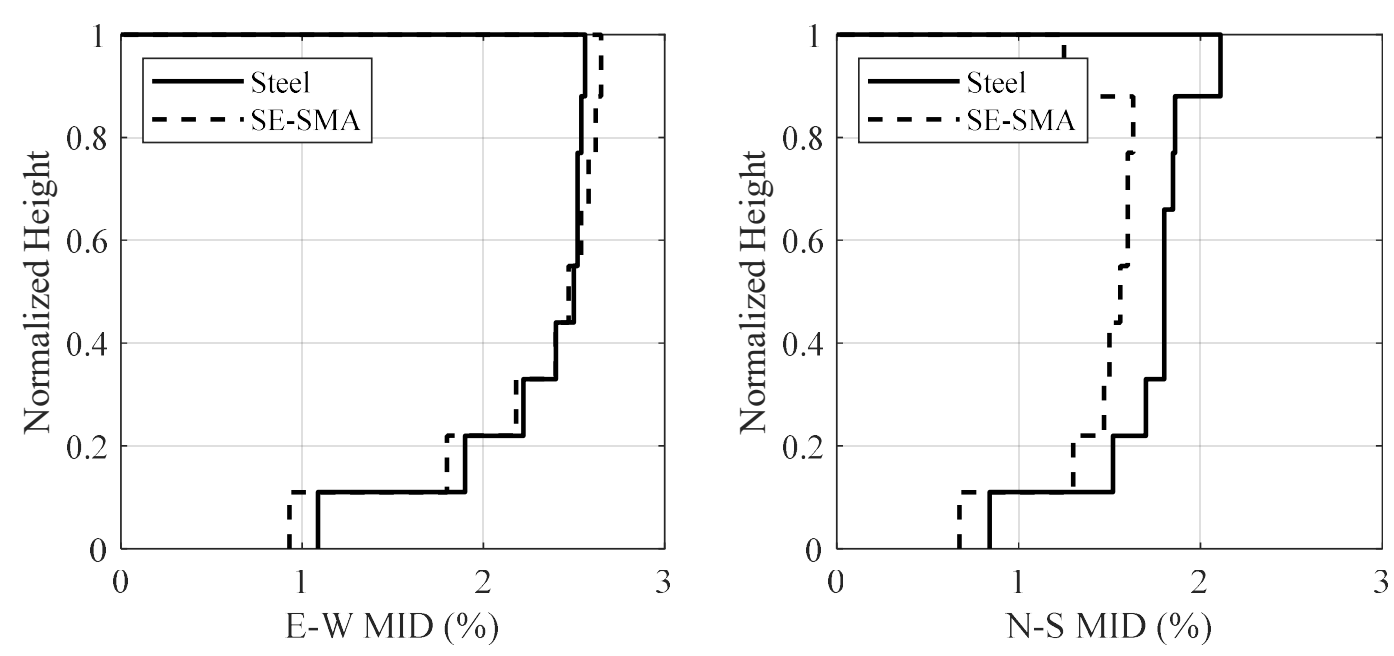

(b)
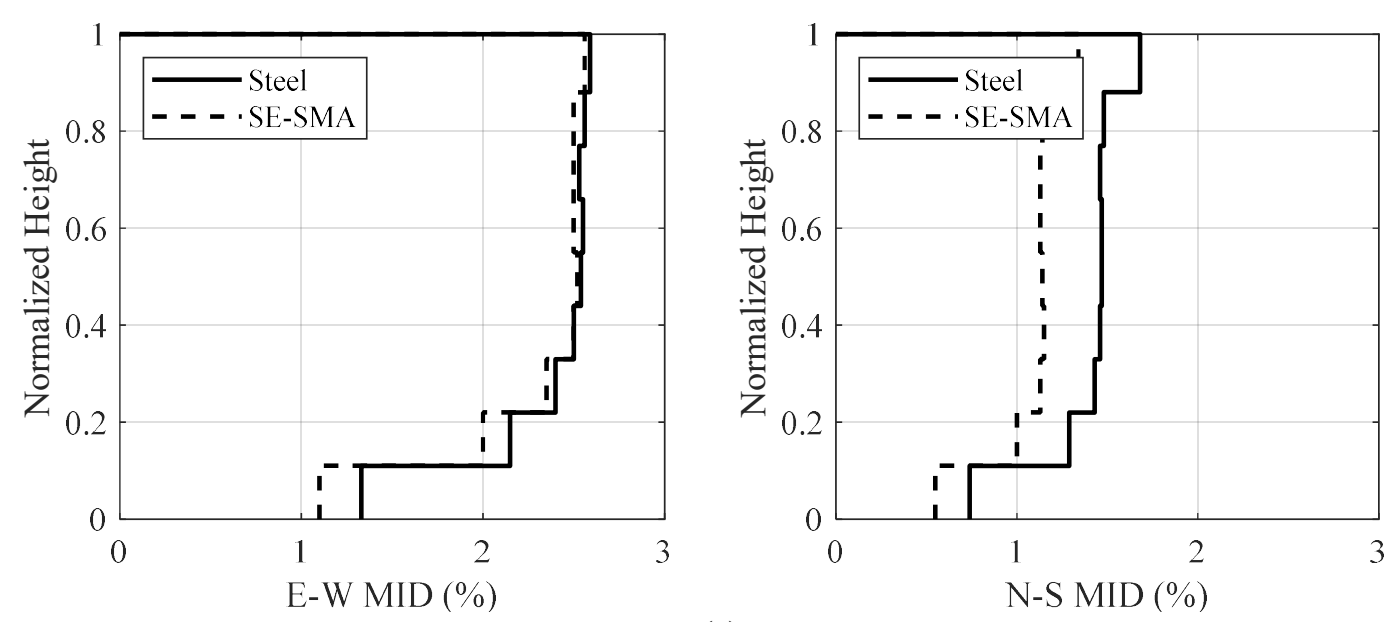

(c)

Figure 11. Mean inter-story drift ratios: (a) 5\% Eccentricity; (b) 10\% Eccentricity; (c) 20\% Eccentricity 
The influence of mass eccentricity on residual displacements is illustrated in Figure 12. Utilizing SMA bars has reduced the residual roof displacements by $39 \%, 36 \%$, and $35 \%$ in the N-S direction and by $50 \%, 32 \%$, and $30 \%$ in the $\mathrm{E}-\mathrm{W}$ direction considering torsional eccentricities of $5 \%, 10 \%$, and $20 \%$, respectively.

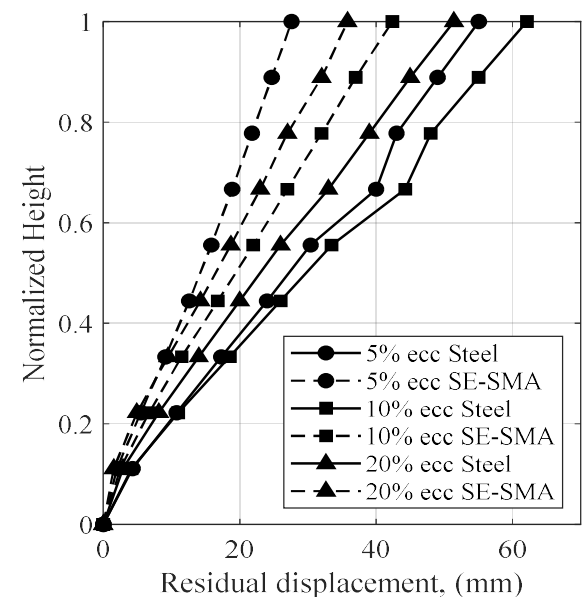

(a)

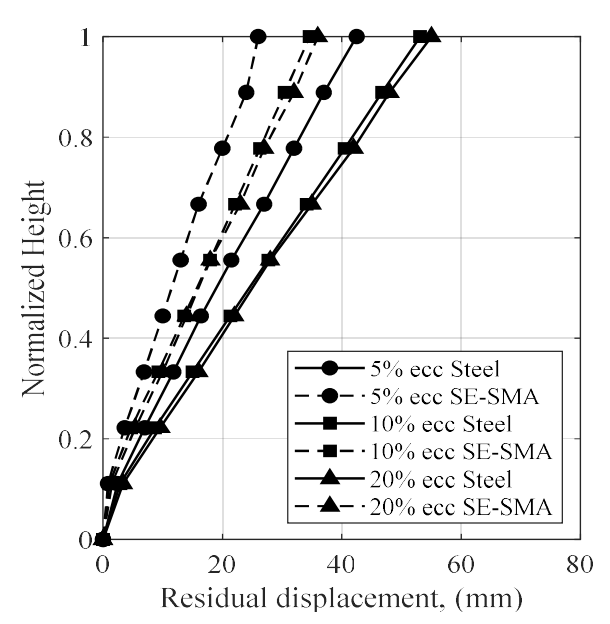

(b)

Figure 12. Mean residual displacements: (a) E-W direction; (b) N-S direction

Torsional ratio $\beta$ is defined as the ratio of the largest maximum story displacement to the average of the maximum and minimum displacement measured in the same direction at the building corners. The $\beta$ values are calculated, considering both E-W and N-S directions, and are shown in Figure 13. In the E-W direction and at 5\% mass eccentricity, the $\beta$ value for the SMA RC core wall is higher than the steel RC core wall but does not exceed the code limit of 1.7. The $\beta$ values at other eccentricities in the E-W and N-S directions are almost the same for steel and SMA RC core walls. This finding confirms that both core walls can be classified as torsionally insensitive for the considered mass eccentricities. 


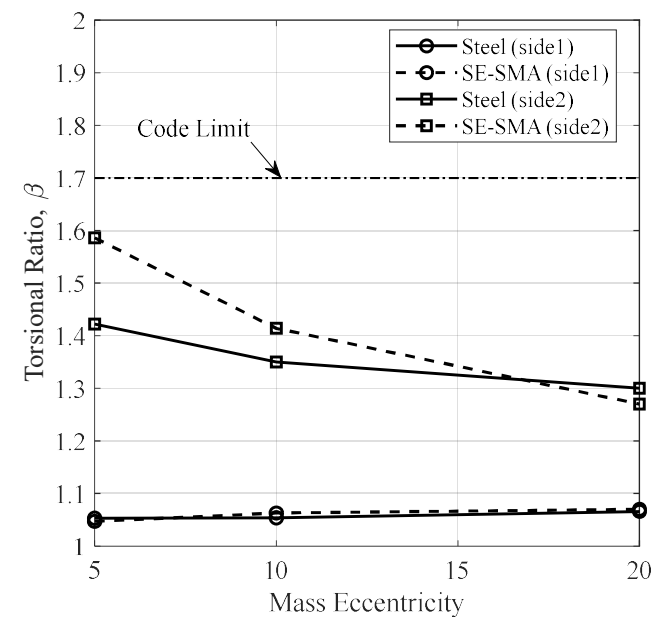

(a)

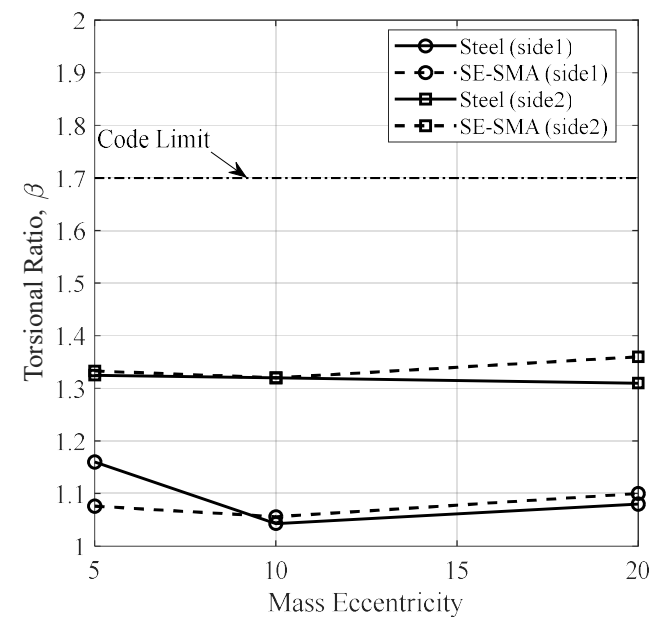

(b)

Figure 13. Mean diaphragm rotations: (a) E-W direction; (b) N-S directions

\subsection{Bidirectional seismic excitations}

Ground motions are applied simultaneously in each direction (36 cases in total). The response of the steel and SMA RC core walls is compared in terms of the mean peak acceleration at the top floor and the mean lateral displacement at the roof level, as shown in Figures 14 and 15. In both directions, the floor acceleration of the SMA RC wall is lower than the steel $\mathrm{RC}$ core wall considering different mass eccentricities. This reduction becomes negligible with the increase in the mass eccentricity due to the higher flexibility for both core walls, as shown in Table 1 .

The difference in lateral displacements between the two considered core walls in the E-W direction is minor considering unidirectional or bidirectional seismic excitations. In the N-S direction, the SMA RC core wall exhibits a lower lateral displacement when subjected to unidirectional excitation as compared to the steel RC core wall considering $10 \%$ and $20 \%$ torsional eccentricity. However, under bidirectional excitation, both walls exhibit the same lateral displacement. 


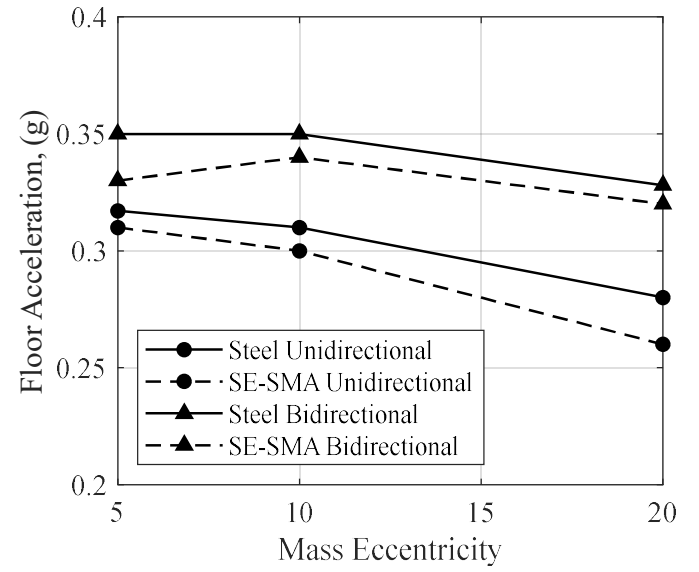

(a)

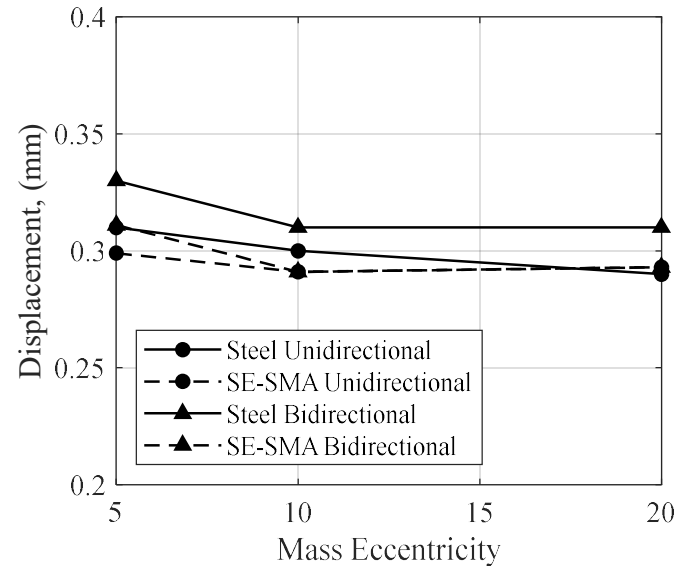

(b)

Figure 14. Mean roof accelerations under unidirectional and bidirectional excitations: (a) E-W direction; (b) N-S direction

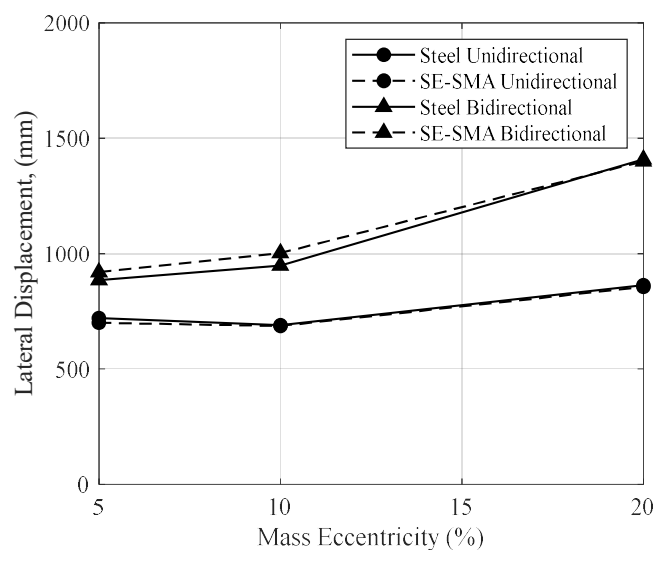

(a)

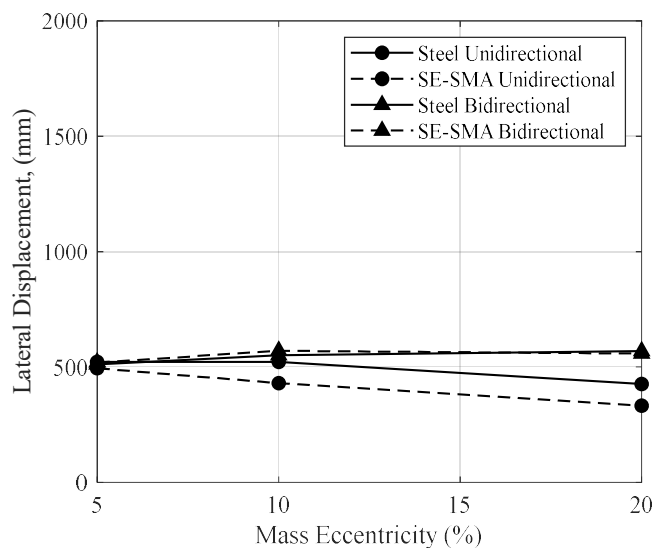

(b)

Figure 15. Mean lateral displacements under unidirectional and bidirectional excitations: (a) E-W direction; (b) N-S direction

Figure 16 shows the mean residual displacement in both directions. In the E-W direction and for all torsional eccentricities, the use of SMA bars reduced the residual displacements for unidirectional and bidirectional ground motions by $45 \%$ on average. The re-centering capability of SMA is reduced by increasing the mass eccentricity due to the increase in structural flexibility. In the E-W direction, the SMA core wall exhibits 37\%, 50\%, and 57\% lower residual displacement as compared to steel $\mathrm{RC}$ core walls for $5 \%, 10 \%$, and $20 \%$ torsional eccentricities, respectively. 
Figure 17 shows a comparison between the residual displacement at the building corner for both core walls. The in-plane residual displacements of the SMA RC core wall is lower than the steel RC core wall by $53 \%, 36 \%$, and $35 \%$ for $5 \%, 10 \%$, and $20 \%$ torsional eccentricities, respectively. The difference between bidirectional and unidirectional cases is negligible at higher torsional eccentricities.

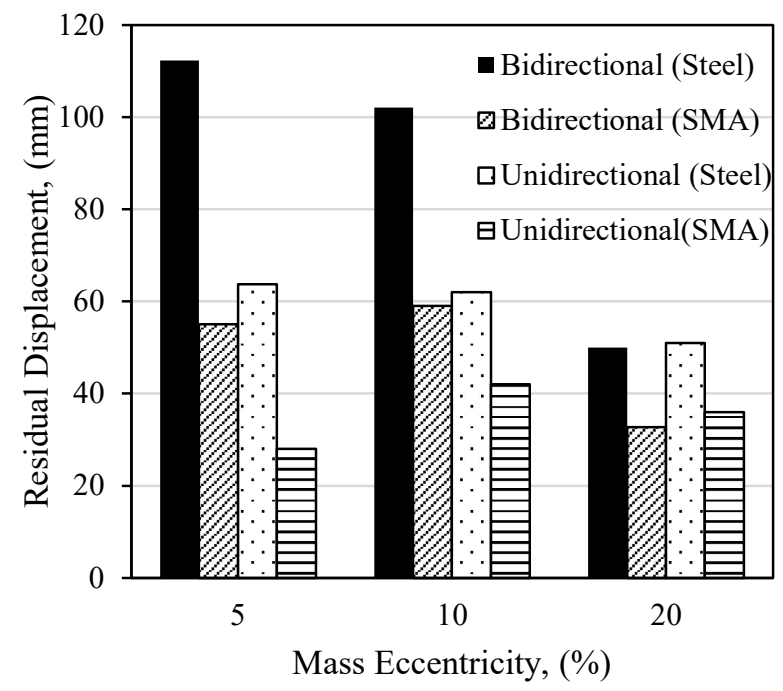

(a)

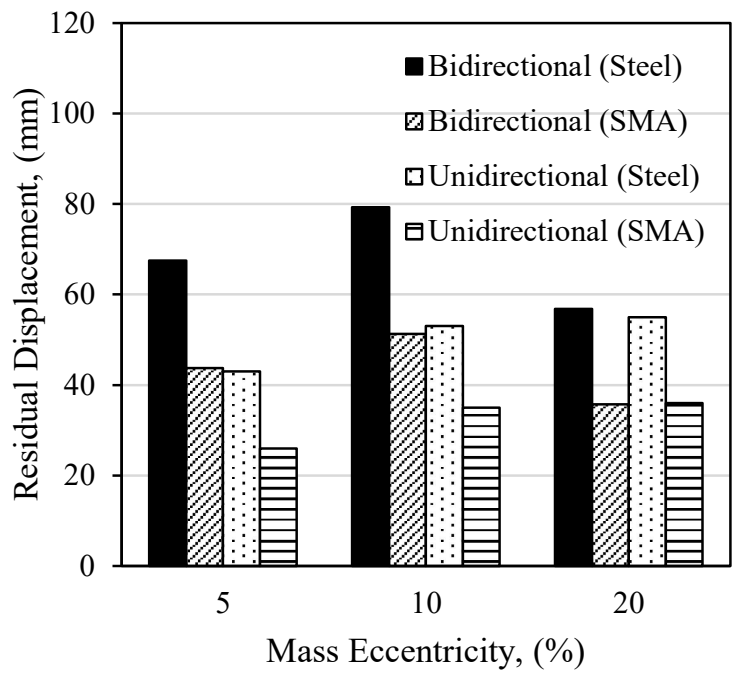

(b)

Figure 16. Mean residual displacements under unidirectional and bidirectional excitations:

(a) E-W direction; (b) N-S direction

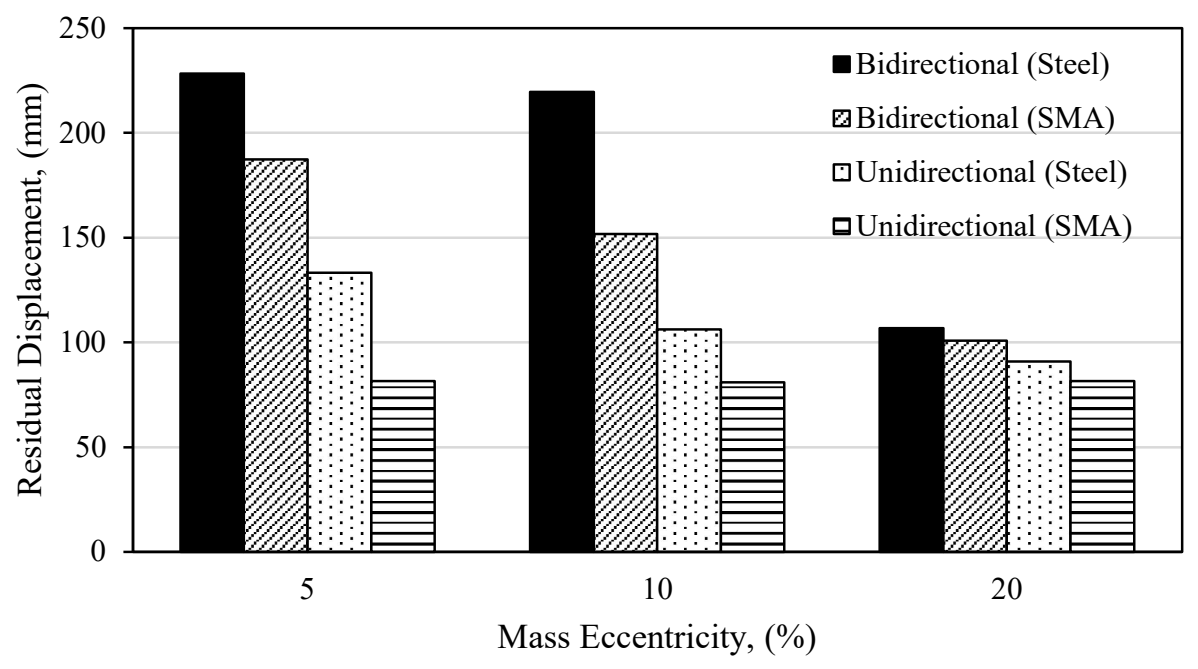

Figure 17. Mean residual displacement at building corner under unidirectional and bidirectional excitations 
Tables 3 and 4 summarize the mean inter-story drift ratios (MIDs) and the mean residual interstory drift ratios (MRIDs) for both walls considering different mass eccentricities. The difference between the considered walls in terms of MID is minimal as compared to MRID values. For instance, the SMA RC core wall at $20 \%$ eccentricity had a $2.0 \%$ MID as compared to $1.8 \%$ MID for the steel RC core wall. Regardless of the reinforcement type, the effect of bidirectional excitation on the MID results is large. For the bidirectional excitation in the E-W direction, the MRID for steel RC core wall reaches a maximum value of $0.5 \%$ and $0.43 \%$ for mass eccentricities of $5 \%$ and $10 \%$, respectively. Using SMA bars reduces the MRID by $42 \%$ and $33 \%$ for $5 \%$ and $10 \%$ mass eccentricity, respectively. 
Table 3. MIDs and MRIDs for E-W direction mass eccentricity

\begin{tabular}{|c|c|c|c|c|c|c|c|c|c|c|c|c|}
\hline & \multicolumn{12}{|c|}{ Mass Eccentricity in E-W direction (\%) } \\
\hline & \multicolumn{4}{|c|}{5} & \multicolumn{4}{|c|}{10} & \multicolumn{4}{|c|}{20} \\
\hline & \multicolumn{2}{|c|}{ Steel } & \multicolumn{2}{|c|}{ SMA } & \multicolumn{2}{|c|}{ Steel } & \multicolumn{2}{|c|}{ SMA } & \multicolumn{2}{|c|}{ Steel } & \multicolumn{2}{|c|}{ SMA } \\
\hline & MID (\%) & $\begin{array}{c}\text { MRID } \\
(\%)\end{array}$ & MID (\%) & $\begin{array}{c}\text { MRID } \\
(\%)\end{array}$ & MID (\%) & $\begin{array}{c}\text { MRID } \\
(\%)\end{array}$ & MID (\%) & $\begin{array}{c}\text { MRID } \\
(\%)\end{array}$ & MID (\%) & $\begin{array}{c}\text { MRID } \\
(\%)\end{array}$ & MID (\%) & $\begin{array}{c}\text { MRID } \\
(\%)\end{array}$ \\
\hline Unidirectional & 2.23 & 0.20 & 2.26 & 0.19 & 2.25 & 0.24 & 2.23 & 0.18 & 2.25 & 0.21 & 2.25 & 0.13 \\
\hline Bidirectional & 2.56 & 0.50 & 2.56 & 0.29 & 2.50 & 0.43 & 2.40 & 0.30 & 2.63 & 0.21 & 2.50 & 0.19 \\
\hline
\end{tabular}

Table 4. MIDs and MRIDs for N-S direction mass eccentricity

\begin{tabular}{|c|c|c|c|c|c|c|c|c|c|c|c|c|}
\hline & \multicolumn{12}{|c|}{ Mass Eccentricity in N-S direction (\%) } \\
\hline & \multicolumn{4}{|c|}{5} & \multicolumn{4}{|c|}{10} & \multicolumn{4}{|c|}{20} \\
\hline & \multicolumn{2}{|c|}{ Steel } & \multicolumn{2}{|c|}{ SMA } & \multicolumn{2}{|c|}{ Steel } & \multicolumn{2}{|c|}{ SMA } & \multicolumn{2}{|c|}{ Steel } & \multicolumn{2}{|c|}{ SMA } \\
\hline & MID (\%) & $\begin{array}{c}\text { MRID } \\
(\%)\end{array}$ & MID (\%) & $\begin{array}{c}\text { MRID } \\
(\%)\end{array}$ & MID (\%) & $\begin{array}{l}\text { MRID } \\
(\%)\end{array}$ & MID (\%) & $\begin{array}{c}\text { MRID } \\
(\%)\end{array}$ & MID (\%) & $\begin{array}{c}\text { MRID } \\
(\%)\end{array}$ & MID (\%) & $\begin{array}{c}\text { MRID } \\
(\%)\end{array}$ \\
\hline Unidirectional & 1.49 & 0.10 & 1.42 & 0.06 & 1.43 & 0.21 & 1.46 & 0.14 & 1.56 & 0.11 & 1.58 & 0.02 \\
\hline Bidirectional & 1.75 & 0.18 & 1.78 & 0.07 & 1.6 & 0.31 & 1.78 & 0.21 & 1.81 & 0.23 & 1.99 & 0.13 \\
\hline
\end{tabular}




\section{Conclusions}

The seismic performance of steel RC and SMA RC core walls with different mass eccentricity is investigated in this study. Floor acceleration, residual displacement, diaphragm rotations, and residual diaphragm rotations are evaluated under unidirectional and bidirectional seismic ground motions. The following conclusions can be drawn from this study:

1- The use of the SMA RC core wall will reduce the damage of non-structural components as they had reduced floor accelerations as compared to the steel RC core wall. This benefit is more apparent for mass eccentricities higher than $10 \%$.

2- Floor accelerations resulting from unidirectional excitations are lower than that those from bidirectional excitations. However, for both cases, the SMA bars attenuated the floor accelerations.

3- The steel RC core wall and the SMA RC wall exhibited the same lateral displacement envelopes for all mass eccentricities.

4- Utilizing SMA bars in the plastic hinge substantially reduces the residual displacements, $36 \%$ on average, caused by unidirectional and bidirectional excitations, but the rate of this reduction reduces with increasing the mass eccentricity.

5- SMA bars reduce the diaphragm rotations by $6 \%$ to $58 \%$. The maximum diaphragm rotations for both walls occur at 5\% mass eccentricity. Therefore, this mass eccentricity is adequate to account for the torsional amplification for static or dynamic analysis.

\section{Acknowledgments}

The authors are grateful for the financial support provided by the Natural Sciences and Engineering Research Council of Canada (NSERC). 


\section{REFERENCES}

[1] Aguilar J, Juarez H, Ortega R, Iglesias J. The Mexico earthquake of September 19,1985-statistics of damage and of retrofitting techniques in reinforced concrete buildings affected by the 1985 earthquake. Earthquake Spectra 1989; 5(1): 145-151.

[2] Tsai K C, Chiang P H, Bruneau M. Overview of Building Damages in 921 Chi-Chi Earthquake. Earthquake. Engineering and Engineering Seismology 2000; 2(1): 93-108.

[3] Elwood K J, Pampanin S, Kam W Y. February 2011 Christchurch earthquake and implications for the design of concrete structures. In Proceedings of the International Symposium on Engineering Lessons Learned from the 2011 Great East Japan Earthquake 2011; (pp. 1157-1168).

[4] Westenenk B, de la L J, Besa J, Jünemann R, Moehle J, Lüders C, Hwang S J. Response of reinforced concrete buildings in concepcion during the Maule earthquake. Earthquake Spectra 2012; 28(S1): S257-S280.

[5] Riva P, Meda A, Giruriani E. Cyclic behaviour of a full scale RC structural wall. Engineering Structures 2003; 25(6): 835-845.

[6] Su R, Wong S M. Seismic behaviour of slender reinforced concrete shear walls under high axial load ratio. Engineering Structures 2007; 29(8): 1957-1965.

[7] Ganesan N, Abraham R, Beena P, Anil R. Influence of horizontal reinforcement on ultra high performance concrete wall panels under two way in plane action. International Journal of Scientific \& Engineering Research 2013; 4(5): 149-152.

[8] Paulay T, Priestley M. Stability of ductile structural walls. ACI Structural Journal 1993; 90(4).

[9] Chai Y H, Elayer D T. Lateral stability of reinforced concrete columns under axial reversed cyclic tension and compression. Structural Journal 1999; 96(5): 780-790.

[10] P'egon C, Plumier A, Pinto J, Molina P, Gonzalez P C, Hubert, O. U-shaped walls: Description of the experimental test set-up. Ispra, Italy: Technical report 2000, TMR-ICONS-TOPIC 5, JRC.

[11] Beyer K. Seismic design of torsionally eccentric buildings with U-shaped RC walls. Pavia, Italy: Ph.D. thesis 2007: European School for Advanced Studies in Reduction of Seismic Risk (Rose School).

[12] Lowes 1, Lehman D, Kuchma D, Mock A, Behrouzi A. Large scale tests of C-shaped reinforced concrete walls. summary report from nees project warehouse. Technical report 2013, NEES project.

[13] Hashemi A, Masoudnia R, Quenneville P. Seismic performance of hybrid self-centring steel-timber rocking core walls with slip friction connections. J Constr Steel Res 2016; 126: 201-213.

[14] Di Cesare A, Ponzo F, Nigro D, Pampanin S, Smith T. Shaking table testing of post-tensioned timber frame building with passive energy dissipation systems. Bull Earthq Eng 2017; 15(10): 4475-4498.

[15] Abraik E, Youssef M. Seismic Fragility assessment of superelastic shape memory alloy reinforced concrete shear walls. Journal of building engineering 2018; 19: 142-153.

[16] Alam M S, Youssef M A, Nehdi M. Utilizing shape memory alloys to enhance the performance and safety of civil infrastructure: a review. Canadian Journal of Civil Engineering 2007; 34(9): 1075-1086

[17] Yang CSW, DesRoches R, Leon RT. Design and analysis of braced frames with shape memory alloy and energyabsorbing hybrid devices. Eng Struct 2010; 32(2): 498-507.

[18] Qiu C, Li H, Ji K, Hou H, Tian L. Performance-based plastic design approach for multi-story self-centering concentrically braced frames using SMA braces. Eng Struct 2017; 153: 628-38. 
[19] Youssef MA, Alam MS, Nehdi M. Experimental investigation on the seismic behavior of beam-column joints reinforced with superelastic shape memory alloys. J Earthquake Eng 2008; 12(7): 1205-22.

[20] Saiidi MS, Sadrossadat-Zadeh M, Ayoub C, Itani A. Pilot study of behavior of concrete beams reinforced with shape memory alloys. J Mater Civ Eng 2007; 19(6) :454-61.

[21] Abdulridha A, Palermo D, Foo S, Vecchio FJ. Behavior and modeling of superelastic shape memory alloy reinforced concrete beams. Eng Struct 2013; 49: 893-904.

[22] Wang W, Fang C, Liu J. Self-centering beam-to-column connections with combined superelastic SMA bolts and steel angles. J Struct Eng 2016; 143(2):04016175.

[23] Sultana P, Youssef MA. Seismic performance of modular steel frames equipped with shape memory alloy braces. Bull Earthq Eng 2018; 16(11):5503-27.

[24] Zheng Y, Dong Y, Li Y. Resilience and life-cycle performance of smart bridges with shape memory alloy (SMA)cable-based bearings. Constr Build Mater 2018; 158:389-400.

[25] Zafar A, Andrawes B. Seismic behavior of SMA-FRP reinforced concrete frames under sequential seismic hazard. Eng Struct 2015; 98: 163-73.

[26] Bingle J. Innovative Materials to Improve Bridge Seismic Resilience. Structure Magazine, Building Blocks, March 2019.

[27] Abdulridha A. Performance of superelastic shape memory alloy reinforced concrete elements subjected to monotonic and cyclic loading. Ottawa: Ph.D. 2012. thesis: University of Ottawa.

[28] Abraik E, Youssef M. Cyclic performance of shape memory alloy reinforced concrete walls. Response of structures under extreme loading (pp. 326-333). Lansing, MI 2015: The fifth international workshop on performance, protection, and strength of structures under extreme loading.

[29] Abraik E, Youssef M. Performance assessment of three-story shape memory alloy reinforced concrete walls. CSCE 5th International Structural Specialty Conference 2016; 852. London, ON, Canada.

[30] Effendy E, Liao W, Song G, Mo Y, Loh C. Seismic behavior of low rise shear walls with SMA bars. Earth \& Space 2006: 3, 377-388.

[31] Clough R W, King I P, Wilson E L. Structural analysis of multistory buildings. Journal of the Structural Division 1964; 90(3): 19-34.

[32] Macleod I A, Hosny H M. (1977). Frame analysis of shear wall cores. Journal of the Structural Division 1977; 103(10): 2037-2047.

[33] Beyer K, Dazio A, Priestley M J. Inelastic wide-column models for U-shaped reinforced concrete walls. Journal of Earthquake Engineering 2008; 12(S1): 1-33.

[34] OpenSees. (2018). Open system for earthquake engineering simulation. Berkeley, CA.

[35] Stafford-Smith B, Girgis A. Deficiencies in the wide column analogy for shear wall core analysis. Concrete International 1986; 8(4): 58-61.

[36] Mander J B, Priestley M J. Theoretical stress-strain model for confined concrete. Journal of Structural Engineering. ASCE 1988; 114(8): 1804-1826.

[37] Menegotto M. Pinto E. Method of analysis of cyclically loaded RC plane frames including changes in geometry and non-elastic behavior of elements under normal force and bending. Preliminary Report IABSE 1973; vol 13. 
[38] Christopoulos C, Tremblay R, Kim H, Lacerte M. (2008). Self-centering energy dissipative bracing system for the seismic resistance of structures: development and validation. ASCE Journal of Structural Engineering 2008; 134(1): 96-107.

[39] TBI. (2017). Guidelines for performance-based seismic design of tall buildings, Report No. 2017/06. Berkeley, CA: University of California.

[40] Panagiotou M. Seismic design, testing, and analysis of reinforced concrete wall buildings. San Diego, CA: Ph.D. thesis 2008: UC: San Diego.

[41] A23.3-14. (2014). Design of Concrete Structures. Canadian Standards Association. Mississauga, ON, Canada.

[42] The National Building Code of Canada (NBCC). Ottawa: Canadian Commission on Building and Fire Code, National Research Council 2015.

[43] Beyer K, Dazio A, Priestley M J N. Quasi-static cyclic tests of two U-shaped reinforced concrete walls. Journal of earthquake engineering 2008; 12(7): 1023-1053.

[44] PEER. Berry M, Parrish M, Eberhard M. PEER Structural Performance Database, User's Manual (Version 1.0). University of California, Berkeley; 2004. 